\title{
NATIVE ADVERTISING USED AS A NEW ADVERTISING MODEL IN SOCIAL MEDIA
}

\author{
DOI: 10.17261/Pressacademia.2019.1103 \\ PAP-V.9-2019(50)-p.269-273
}

\section{Elif Arslan}

Istanbul Esenyurt University, School of Applied Sciences, İstanbul, Türkiye

elifarslan@esenyurt.edu.tr, ORCID: 0000-0001-5000-7479

To cite this document

Arslan, E., (2019). Native advertising used as a new advertising model in social media PressAcademia Procedia (PAP), V.9, p.269-273

Permemant link to this document: http://doi.org/10.17261/Pressacademia.2019.1103

Copyright: Published by PressAcademia and limited licenced re-use rights only.

\section{ABSTRACT}

Purpose- In the last two decades, the importance of internet advertising has grown with the rapidly developing technology and it is delivered to the consumers by various digital methods. Banners, advertors and search engine advertisements are the most widely used types of internet advertising. However, there has been a consumer structure that has recently moved away from the advertisement due to the penetration of too many advertisements to the consumer and the emergence of the advertising content through the creation of a conscious consumer profile. For this reason, different types of internet advertising have come to the forefront in order to attract the attention of consumers who are away from advertising due to the use of various programs that prevent advertisements. One of these is Native Marketing which is expressed as natural advertising platform and it is a kind of internet advertising which is prepared in accordance with the content and visual design of the platform.

Methodology- Social media channels (Youtube, Facebook, Twitter, Instagram), which have become increasingly popular nowadays, have facilitated access to the Internet by mobile devices. In this context, advertisements made on social media are brought the user's preferences and tastes and personalized advertising is being prepared.

Findings- As a natural advertising tool, social media is being used more and more every day and is successful in attracting consumers.

Conclusion- In this study, the concept of natural advertising is examined and the characteristics and types of natural advertising are mentioned. We also compared the advantages and disadvantages, similar and different aspects, by comparing the titles with banner and advertorial marketing with natural advertising. In addition to this, the use of natural advertisements in these media has been examined with the emphasis on social media concept. Finally, examples of natural advertisements on social media networks are included in the paper.

Keywords: Natural advertising, social media, internet advertising, advertorial, banner advertising. JEL Codes: M10, M12

\section{SOSYAL MEDYADA YENI BİR REKLAM MODELI OLARAK KULLANILAN NATIVE (DOĞAL) REKLAM}

\section{ÖZET}

Amaç- Son yirmi yıldır hızla gelişen teknoloji ile internet reklamcılı̆̆ının önemi artmış ve işletmeler tarafından çeşitli dijital yöntemlerle tüketicilere ulaştırılmaya çalışılmaktadır. Kullanılan bu stratejilerden özellikle Banner reklamlar, advertoriallar, arama motoru reklamları internet reklamcılığının en çok kullanılan türleridir. Ancak son zamanlarda çok fazla reklamın tüketiciye nüfuz etmesinden ve bilinçli tüketici profili oluşarak reklam içeriğinin arzının ortaya çıkmasından dolayı reklamdan uzaklaşan bir tüketici yapısı meydana gelmiştir. Bundan dolayı günümüzde reklamları engelleyici çeşitli programların kullanılması nedeniyle reklamdan uzaklaşan tüketicilerin ilgisini çekmek adına farklı internet reklamcılık çeşitleri ön plana çıkmıştır. Bunlardan biri de "Native Marketing” yani "doğal reklamcılık" olarak ifade edilen ve bulunduğu platformun içeriğine ve görsel tasarımına uygun olarak hazırlanan bir internet reklamcılık türüdür.

Yöntem- Günümüzde popülerliği artan sosyal medya mecraları(Youtube, Facebook, Twitter, Instagram) tüketicinin mobil cihazlarla internete erişimini kolaylaştırmıştır. Bu bağlamda sosyal medya üzerinden yapılan reklamlar kullanıcının tercih ve beğenilerini ön plana taşıyarak, kişiye özel reklam hazırlaması yapılmaktadır.

Bulgular- Doğal reklam aracı olarak sosyal medya gün geçtikçe daha fazla kullanılmakta ve tüketicinin beğenisini çekme yönünde başarılı olmaktadır.

Sonuç- Bu çalışmada doğal reklamcılık kavramı incelenerek, doğal reklamcılığın özellikleri ve türlerinden bahsedilmiştir. Ayrıca doğal reklam ile banner ve advertorial pazarlama ile başlıkları karşılaştırılarak, avantaj ve dezavantajları, benzer ve farklı yönleri ele alınmıştır. Bununla birlikte sosyal medya kavramı üzerinde durularak, doğal reklamların bu mecralardaki kullanımları konusu incelenmiştir. Son olarak da sosyal medya ağları üzerinde yapılan doğal reklam örneklerine yer verilmiştir.

Anahtar Kelimeler: Doğal reklam, sosyal medya, internet reklamcılığı, advertorial, banner reklam. JEL Kodları: M10, M12 


\section{GiRiş}

Gün geçtikçe artan internet talebi ve değişen tüketici davranışları web yapısının Web 1.0'dan Web 2.0 tarzına değişmesine yol açmıştır. Tek taraflı iletişime olanak veren Web 1.0, kullanııılarına sadece bilgiye ulaşma olanağı vermekteydi. Ancak Web 2.0 ise interaktif iletişime olanak sağlayıp, kullanıııların hem yorum yapmasına, bilgiyi paylaşmasına ve geri dönüşler yapmasına imkan tanır. Ayrıca her kullanıcı kendine has içerik üreticisi haline gelmiştir. Bu içerikleri kullanıp, paylaşma olanağına sahiptir. Bu olanağa imkan veren sosyal medyada kullanılan pazarlama çalışmaları günden güne değişmektedir. Kullanıcısına reklam olduğunu fark ettirmeden içerikler sunan Native (Doğal) reklam çalışmaları, geleneksel reklam algılarını yıkarak tüketicinin ilgisini çekmeye çalışmaktadır.

\subsection{Sosyal Medya Kavramı ve Özellikleri}

Sosyal medya, sosyal ağların ve grupların oluşturduğu; insanların birbirleriyle iletişime geçtikleri, ürün satın aldıkları, düşünce ve nesnelere ilişkin ortak paydada buluştukları, en yüksek derecede paylaşımın gerçekleştiği sanal platformdur(Vural ve Bat, 2010: 3351). Kişilerin fotoğraf, video, reklam, görüntü, yazı, makale, haber ve düşüncelerini paylaştığı çevrimiçi (online) kaynaklardır. Sosyal medya kullanıcılarına karşılıkı iletişim imkânı sunan, kullanıcılarının bireysel veya gruplar halinde medya içeriği oluşturmasını sağlayan dijital medya teknolojileridir(Erbaşlar, 2013: 6). Müşterilerin ilgi alanlarının belirlenmesi ve isteklerinin tespiti konusunda sosyal medya önemli bir araçtır(Karkar, 2016: 340).

Oluşturulacak doğru bir sosyal medya stratejisi markanın tüketicilerle doğru etkileşimini sağlayarak doğru hedef kitleye ulaşılmasını sağlar(Erbaşlar, 2013: 43). Uygun mecralarda yer alan markaların sosyal kimliklerini kabul ettirme olanakları artar ve prestij artışı sağlar. Ağızdan ağıza pazarlama yoluyla tanınırlık artar, maliyetler düşer. Yapılan çalışmaların geri dönüşü görüldüğünden, başarı oranları tespiti kolaylaşır.

Tablo 1: Sosyal Medya ile Geleneksel Medya Karşılaştırılması (Erbaşlar, 2013: 17).

\begin{tabular}{|l|l|}
\hline Sosyal Medya & Geleneksel Medya \\
\hline iki yönlü iletişim & Tek yönlü iletişim \\
\hline Açık sistem & Kapalı sistem \\
\hline Şeffaf & Opak \\
\hline Birebir pazarlama & Kitle pazarlama \\
\hline Marka ve kullanıcı tarafından oluşturulan içerik & Profesyonel içerik \\
\hline Yapılandırmamış iletişim & Kontrollü iletişim \\
\hline Gerçek zamanlı oluşum & Önceden üretilen/planlanan \\
\hline Gayri resmi dil & Resmi dil \\
\hline Aktif katııımı & Pasif tutulum \\
\hline
\end{tabular}

Sosyal medya markaların, marka tanınırlığı ve itibarını arttırmak için, rekabet üstünlüğü sağlamak için kullanılması gereken bir mecra haline gelmiştir(Erbaşlar, 2013: 20).

Geleneksel medyada içerik üretmek özel şirketler veya hükümetin kontrolündeyken, sosyal medyada herkes tarafından kullanılabilen az maliyetli içeriklerdir. Sosyal medya kullanıcılarının belli bir eğitim almasına gerek duyulmaksızın, içerik üretebilmekte ve paylaşabilmektedir. Sosyal medya gündemine göre geleneksel medya araçları kullanılmaktadır. Geleneksel medya araçları oluşturulduktan sonra değiştirilmesi zordur. Ancak sosyal medya mecralarında değişim kısa sürede yapılabilir, hatta kullanıcı yorumlarına ve geri bildirimlerine göre revize edilebilir.

\subsection{Sosyal medyanın özelliklerine bakacak olursak(Mayfield, 2019: 5);}

Katıımcılar: Sosyal medya herkesin katııımını ve geri bildirimini teşvik eder. Medya ile kullanıcı arasındaki çizgiyi ortadan kaldırır. Açıklık: Sosyal medya araçlarının çoğu katılıma ve geri bildirime açıktır. Kullanıııları oy kullanmaya, yorum yapmaya ve bilgi paylaşmaya teşvik eder. İçerik paylaşırken kullanıcıları en az engelle karşılaştıııken, parola ile kişisel bilgilerini korumasını sağlar. İletişim: Geleneksel medya aksine iletişim çift yönlüdür. Geleneksel medyada içerik kullanıcısına iletilir. Ancak sosyal medyada geri dönüşlere izin verdiğinden interaktif iletişim söz konusudur. Toplum: Sosyal medya toplulukların hızlı ve etkili bir şekilde oluşmasını sağlar. Toplumun çeşitli politik konularda, video veya fotoğraf paylaşımı gibi ortak konularda fikir alışverişi yapacağı ortam sağlamaktadır. Bağlantı Kurma: Çoğu sosyal medya mecraları, birbirleriyle olan bağlantılarını kurarak, site, kaynak ve insan bağlantısını güçlendirerek daha çok alana ulaşabilir.

\subsection{Native (Doğal) Reklam Kavramı}

Internetin çığır açtığı son yirmi yııldan bu yana internet reklamcılığı çeşitli yöntemlerle tüketicilere ulaştııılmaktadır. Banner reklamlar, advertoriallar, arama motoru reklamları halen internet reklamcilığını \%40'ını oluşturmaktadır(Arslan, 2017: 21). Ancak tüketicilerin içeriğe önem vermesinden ve internet üzerinde sürekli reklamlara maruz kalmadan dolayı kaçınma davranışı ortaya çıkmışır. Reklamları engelleyici çeşitli programların kullanılması ve reklamdan uzaklaşan tüketiciler için başka tarz internet reklamcılık çeşitleri ön plana çıkmışır. Bunlardan biri de native marketing adını alan, doğal reklamcılık olarak ifade edilen yeni bir internet reklamcılığı türü olmuştur.

"Native Advertising" olarak kullanılan yöntem Türkiye pazarlama literatürüne "Doğal Reklamclık" olarak girmiştir. Temel olarak doğal pazarlama; hazırlanan reklam içeriğinin sunulduğu mecraya (sosyal medya kanalı, haber siteleri vb.) uygun bir formatta hazırlanmasıdır. Örneğin sosyal içerik platformu olan Onedio platformunda yayınlanacak bir reklam bu sitenin formatına ve dizaynına göre hazırlanır. Doğallık sağlanmış olur. Doğal reklam kullanan firmalar satış yapma amacından çok tüketici ile marka arasında uzun süreli ve kalıcı ilişkiler kurmayı amaçlamaktadır (Pike, 2014: 24). 
Dvorkin(2013)'e göre doğal reklam bir markanın içerik pazarlamasını destekleyen ve buna uygun hazırlanan video, yazı metni ya da editoryal içeriğin ödeme karşılığında dijital ortamlara yerleştirilmesidir(Arslan 2017: 566). İnternet üzerinde yer alan oyunlar, paylaşılan videolar, blog yazıları, sosyal medya araçları aracılığıyla yapılan doğal reklam uygulamaları kullanıcıların bunu görüp, sosyal çevresiyle paylaşması reklamın bir diğer değerli olgusudur.

En iyi 3 “içerik keşif” platformları; 2007'de kurulan Taboola, insanları içeriğe bağlayan bir içerik keşif platformudur. 2006 yılında kurulan Outbrain, nitelikli trafiği ve geliri artırmak için “önerilen bağlantılar” sunmaktadır. Yahoo'nun doğal reklamcılık için girişimi olan Gemini; 2015 yılının Şubat ayında piyasaya sürülmüştür. Yahoo, çeşitli Yahoo web mülklerine (Yahoo Finance gibi), üçüncü şahıslara ve uygulamalara ilgi duyan kitleyi hedefleyen tescilli veri sinyallerini kullanır.

2013 yılında The Atlantic dergisinde ilk doğal reklam örneği yayınlanmıştır. Scientology Kilisesi'nin belli bir ücret karşılığında kilise ve Scientology inancı hakkında bir makale yazılmasını istemiştir. Makalenin sol üst köşesinde "sponsor içeriği" yazmakta, fare ile üzerine gelindiğinde "Bu nedir?” sorusu gözükmekteydi. Doğal reklamın ilk örneği olan bu reklam, okuyucuları tepkisini çekmesinden dolayı, internet sayfasının aşağı kısımlarına taşınmıştır (Çetinkaya, 2016:126).

Doğal reklam editoryal içerik kabul etmez. Seçilen platformun içeriğine uygun ve ücretli yapılır. Ayrıca reklam kutusu yoktur. Platformla uyumlu olduğundan kutu reklamları gibi tüketiciyi rahatsız etmeden genel yayın akışına uygun biçimde tüketiciye sunulur. Yani doğal biçimde sunulur. Özel hazırlanan reklamlar bulundukları platformla aynı tip ve karakterde olduğundan, editoryalle bağlantılı olduğu için doğal reklam adını almıştır. Kullanım hızının arttığı günümüzde doğal reklamlar genellikle test, makale, video, infografik sayfalar ve özel projeler gibi içerik modellerinde kullanılmaktadır (Çetinkaya, 2016: 127). Doğal reklamların öncelikle seçilen hedef kitleye uygun ve seçilen platforma uygun hazırlanması önemlidir. Doğal reklam hazırlanıp uygulandıktan sonra geri dönüşlerin nasıl olduğu ve başarılı olup olmadığını ölçmek gerekecektir. Marka sayfasında geçirilen zaman ve reklamın sağladığı geri dönüş oranları doğal reklamın ölçümlemek için kullanıldığı yöntemlerdir (Kaya, 2017: 17).

\section{NATIVE (DOĞAL) REKLAMIN SOSYAL MEDYADA KULLANIMI}

Ocak 2018 Global Dijital grubun yayınladığı rapora göre interneti kullanan 4 milyardan fazla olduğu saptanmıştır. Dünyada 3 milyardan fazla insan her ay sosyal medyayı kullanıyor, dünya nüfusunun $\% 49$ 'u ise mobil cihazlar ile interneti kullanmaktadır. https://digitalreport.wearesocial.com/ Laptop ya da masa üstünden internete erişim \%43, mobil telefonlardan erişim \%52, tabletlerden erişim \%4, diğer cihazlardan erişim \%0,14'tür. Ayda 2.17 milyar facebook kullanıcısı (bir önceki yıla göre kullanım \%15 artmıştır.) \%88'i mobil cihazlarla giriş yapmaktadır. Ayda 800 milyon kişi instagramı ziyaret etmektedir. Toplamın \%11 ini oluşturmaktadır.

81 milyon nüfuslu Türkiye'de 2018 yılındaki internet kullanımı ve sosyal medya etkisi sonuçlarına bakacak olursak https://digitalreport.wearesocial.com/ (Erişim Tarihi: 08.05.2019);

$\checkmark \quad$ Nüfusun \%67'si ile 54.3 milyon internet kullanıcısı,

$\checkmark \quad$ Nüfusun \%51'i ile 41 milyon aktif sosyal medya kullanıcısı,

$\checkmark \quad$ Nüfusun \%54'ü ile 44 milyon aktif mobil sosyal medya kullanıcısı vardır.

$\checkmark \quad$ Insanlar günün ortalama 7 saatini internette geçirirken, günde ortalama 2 saat $48 \mathrm{dk}$ sosyal medyada, 2 saat $44 \mathrm{dk}$ televizyon başında ve 1 saat $22 \mathrm{dk}$ ise müzik dinleyerek internette vakit geçirmektedir.

$\checkmark \quad$ Similarweb istatistik verilerine göre ülkemizde en çok kullanılan sosyal ağlar sırasıyla; Google.com.tr, youtube, facebook, Google.com, twitter, yandex.com, hürriyet.com, instagram, sahibinden.com, ekşi sözlüktür.

$\checkmark \quad$ Alexa's istatistik verilerine göre ülkemizde en çok kullanılan ağlar sırasıyla; Google.com.tr, youtube, Google.com, sabah.com, haber7.com, facebook, ensonhaber.com, onedio.com, sahibinden.com, instagramdır.

$\checkmark$ Google'da en çok aranan sosyal ağlar ise sırasıyla; facebook, youtube, hava durumu, sahibinden, son dakika, Google, haber, çevir, haberler, instagramdır.

Doğal reklamın en önemli özelliği uygulanacağı mecraya uygun olarak hazırlanmış olmasıdır. Böylelikle tüketici deneyimi sekteye uğramamış olmaktadır. Yayınlandığı platformda doğal reklamla karşılaşan kullanıcı reklamdan ziyade konuyla alakalı faydalı bilgiler alarak, doğal bir şekilde markayı görür ve haberdar olur. Doğal reklam kişiye özeldir. Tüketiciye ait sosyal medya platformunda, onun beğenilerine ve tercihleriyle doğru orantılı reklamlar gösterilir. Doğal reklam ölçümlemesi kullanıcının belli bir sürenin üzerinde zaman geçirmesiyle ücret ödenmesi yapılmaktadır. Ayrıca reklamı gören kişi sayısı, reklamın tıklanma sayısı, kaç kişinin reklama yönlenip gittiği ve siteye gidenlerin kaçının ürünlerden satın aldığı ölçümlenmektedir (Arslan, 2017: 37).

Altı tür doğal reklam çeşidi bulunmaktadır. Yayın içi reklamlar, ücretli arama birimleri, öneri eklentileri, tanıtımlı listeleme, doğal reklam öğeleri içeren kutu içi reklamlar, özel/sınıflandırılamayan doğal reklamlardır (IAB Oyun Kitabı, 2013: 4).

\subsection{Yayın İçi Birimler}

Burada uygulanan doğal reklam çeşidi olan yayın içi reklamlar, bulunduğu platformun içinde yazı karakteri de aynı olacak şekilde yer alarak, okuyucu tarafından reklam olduğu bilinen ve reklama tıklandığında yeni bir sayfada açılan reklamlardır. Link tıklama sayısıyla veya dönüşüm oranıyla etkinliği ölçülmektedir. Yine normal akışa uygun bir biçimde hazırlanmış bir hikâye ile verilen, okuyucunun bulunduğu sayfadan ayrılmadan içeriği okuması veya görüntülemesini sağlayan şekilde olabilmektedir. (IAB Oyun Kitabı 2013: 8) Ayrıca editoryal içeriklerden oluşan haber veya içerik portalları, arama motorları üzerinde yer alan sponsorlu reklamlarda yayın içi birimlerdendir. Yayın içi birimler türünün en çok sosyal medya kanallarında kullanılır. Yayın içi reklamların gösterilirken kullanılan ifadelerden bazıları şöyledir: "reklam”, “ marka sponsorluğunda", "sponsorlu içerik”, " 


\section{3.Ücretli Arama Birimleri(Arama Sonucu Reklamları)}

Yaygın olarak kullanılan ücretli arama sitelerinde karşılaşılan arama sonucu reklamları, arama motorunda yapılan arama sonucunda sonuç sayfasında yer almaktadır. Tüketiciler arama motorlarında arama yaptıkları konuya ilişkin reklamlar ve yönlendirici mesajlara ihtiyaç duymaktadır. Bu reklam türünde aranan kelime ile alakalı çıkan reklamlar yeni bir sayfaya link verilmesiyle görülmektedir. En çok kullanılan arama motorları Yahoo, Google, Yandex, MSN(Bing)dir. Google arama motoruna "elbise" yazılarak arama sonuçlarına bakılınca, ilk olarak karşımıza reklam veren firmalar çıkmaktadır. Sayfanın aşağısına inince kelimeyle ilgili yayınlanan ücretsiz sonuçlar görülmektedir.

\section{4. Öneri Eklentileri}

Sayfanın ana alanına eklenen reklamla birlikte yeni bir linkte açılması şeklindeki reklamlardır. Eklentiler şeklinde iletilen doğal reklam türünde editoryal içeriğin görünümü taklit etmemektedir, farklı bir içerik sunmaktadır. Başka reklam veren tarafından eklenen reklamlarda tüketiciyi bilgilendirmek amaçıı reklam verenin bilgileri bulunmaktadır. "colgate tarafından önerilmiştir" veya trendyol_sponsored şeklinde ifadeler kullanılır. Ayrıca "bu da dikkatinizi çekebilir", "internette diğer sayfalar", "sizin için öneriler" şeklinde ifadeler de kullanılır.

\subsection{Tanıtımlı Listeleme}

Editoryal içeriği olmayan ilan siteleri, alışveriş sitelerinde kullanılan tanıtımlı listeleme yönteminde "Bu nedir?” sorusuna cevap niteliğindeki aramalarda "sponsorlu" etiketiyle kullanılır.

\subsection{Kutu İçi Reklamlar}

Editoryal içerik alanına yerleştirilen kutu şeklinde alanda yer alan reklamlar, içerikle ilişkili bir reklamın verilmesiyle yapılan doğal reklam türüdür. Sayfada açıkça görülerek, ayırt edilmektedir. Normal sayfa içeriğiyle karıştırılmaması için kutu şeklinde sınırları çizilmiştir. Tıklandığında başka bir link açılarak, reklama ilişkin bilgiler verilir.

\subsection{Sınıflandırılamayan/Özel}

Bu reklam türü diğer reklam türlerindeki gibi belli çizgileri olmadığından kendine özgü şekillerde oluşturulmaktadır. Spotify, Tumblr, Flipboard gibi sitelerde kendi doğal reklamlarını oluşturmaktadırlar.

Doğal reklam türlerinin her biri ücret karşılığında yapılan, okuyucunun editoryal içerikten bağımsız olarak reklam olduğunu anlayacağı şekilde belirtilen, reklamın görüntülendiği platform üzerinde dikkat çekici olacak şekilde hazırlanması önemlidir.

\section{DOĞAL REKLAM ILE ADVERTORIAL PAZARLAMA VE BANNER ILE KARŞILAŞTIRILMASI}

Dijital pazarlama altında birçok şekilde yöntemlerle tüketiciye ulaşmak istenmektedir. Advertorial pazarlama uygulamaları ve banner reklamlar en çok kullanılan yöntemler arasındadır. Doğal reklam ile benzerlik gösteren bu kavramların arasındaki farklar bu bölümde incelenmiştir.

\subsection{Doğal Reklam ile Advertorial Pazarlama Karşılaştırılması}

Advertoriallar, bir ürün veya hizmetin direkt tanıtımını yaparak, ürünün faydalarını belirtmek veya satın alınmasını sağlamak amacıyla yapılmış içeriklerdir. Advertorial metin okuyan kişi satışa ilişkin amacı bilmektedir. Metin sonunda "Bu bir reklamdır" ibaresiyle reklam olduğu belirtilmektedir. Doğal reklamla çok benzeyen bu içerik paylaşımının doğal reklamdan farkı, doğal reklamın amacı izleyiciye faydalı bilgiler aldığını hissettirerek, reklam olduğunu belli eden ifadelerden kaçınılır (Arslan, 2016: 573). Sponsorlu reklam veya önerilen içerikler şeklinde ifadelerle içerik sunulur. Ürün ya da hizmetin tanıtımını yapmak veya marka farkındalığı sağlamak, markanın hatırlanmasını sağlamak amacıyla doğal reklam yöntemi kullanılabilir.

Pulizzi'nin 2001 de yaptığı tanıma göre, İçerik pazarlama belirlenmiş hedef kitlenin karlı müşterilere dönüşmesini sağlamak amacıyla ilgili ve istikrarlı içeriğin oluşturulmasını ve dağıtılmasını içeren stratejik pazarlama tekniğidir. İçerik pazarlamada Markalar oluşturdukları web sitesi veya sosyal medya araçlarıyla içeriklerini tüketiciye sunarlar. Marka bulunduğu platforma sahip olduğundan ödeme yapar ve bu ödenmiş medyadır. Ancak doğal reklam kazanılmış medyadır çünkü markalar kendilerine ait platformlardan değil, tüketicilerin kendilerine ait sosyal medya araçlarından ya da farklı mecralardan ulaşırlar. Örneğin markalar youtube kanalında yer alan doğal reklam ile tüketiciye önerilebilir(Arslan, 2016: 575).

\subsection{Doğal Reklam ile Banner Reklam Karşılaştırılması}

En çok kullanılan yöntem olan banner reklamlar, farklı boyutlarda hazırlanarak, bulunduğu platformdan bağımsız olarak hazırlanmış resim, yazı, grafik, video gibi öğelerden oluşan, tıklandığında yeni bir sayfaya yönlendiren ve görüntüleme başına maliyet üzerinden ücretlendirilen sabit veya hareketli reklamlardır(Arslan, 2017: 23).

İnternet kullanıcılarının internette içerik tüketme amacıyla bulunmaları ve reklam önleyici programların keşfi banner reklamların etkinliğini azaltsa da banner reklamlar doğal reklamla iç içe geçmiştir. Banner reklamlar internet sitesi üzerinde içerikten bağımsız olarak, reklam olduğu açıkça belli şekillerde hazırlanarak, başka sayfaya yönlendiren şekillerde hazırlanmıştır. İçerikten uzaklaşan tüketici için bu rahatsız edici olabilmektedir. Ancak doğal reklamlar içerik ve bulunduğu platformun yapısına uygun biçimde hazırlandığından tüketiciyi rahatsız etmemektedir. Genellikle "sponsorlu" diye belirtilen doğal reklamlarda tüketici reklam olduğunun bilincindedir ve internette bulunma amacından uzaklaşmayarak reklam içeriğini incelemektedir. 


\section{SONUÇ}

Günümüzde sosyal medya kullanımının artması ve internete kolay erişim, doğal reklam çalışmalarının bu platformlarda uygulanmasına olanak sağlamıştır. Altı çeşide ayrılan doğal reklamcılık türlerinden her biri internette ve özellikle sosyal medyada kullanılmaktadır. Bu reklam biçimi İlerleyen dönemlerde birçok işletmenin ilgisini çekerek uygulama alanlarının artması beklenmektedir.

\section{KAYNAKÇA}

Arslan E. (2016). "Doğal Reklam: Güncel Bir Internet Reklamcılığı Yöntemi Olarak Doğal Reklamın Tüm Yönleriyle Incelenmesi" Hitit Üniversitesi Sosyal Bilimler Enstitüsü Dergisi, Cilt: 10, Sayı: 1, Haziran 2017, ss. 563-584.

Arslan E. (2017). "Türkiye'de Doğal Reklam: Bir Internet Reklamcılık Yöntemi Olarak Türkiye'de Doğal Reklamcılığın Incelenmesi." Karadeniz Teknik Üniversitesi İletişim Fakültesi Elektronik Dergisi, Cilt: 4, Sayı: 14, p: 20-41.

Çetinkaya A. (2016). "Çevrimiçi Gazetecilikte Yeni Bir Reklam Modeli Olarak Doğal Reklamlar" Online Akademic Journal of Information Technology, Vol:7, Num:25, page: 124-136.

Erbaşlar, G. (2013). "Sosyal Medya'da Mısınız? Asosyal Medya'da Mısınız?" Nobel Yayınevi, Ankara.

https://digitalreport.wearesocial.com/ "We are Social." Erişim tarihi 16.04.2019. (IAB Oyun Kitabı, 2013: 4)

Karkar, A. (2016). "Değer ve Güven Ağlarının Yükselişinde Içerik Pazarlaması" International Journal of Social Sciencies and Education Resarch, Vol: 2, Num: 1, page: 335-348.

Kaya, E. (2017). “Dijital Pazarlama ve Ölçümleme” Isparta.

Mayfield, A. "What is Social Media, iCrossing" e-book, s.5,

https://www.icrossing.com/uk/sites/default/files_uk/insight_pdf_files/What\%20is\%20Social\%20Media_iCrossing_ebook.pdf Erişim Tarihi: 19.05.2019.

Pike G. H. (2014). "Love It or Hate It: Native Advertisin on The Internet" Information Today. Vol: 31, Issue: 5 p: 24.

Vural, Z. B. Ve Bat, M. (2010). "Yeni Bir Iletişim Ortamı Olarak Sosyal Medya: Ege Üniversitesi Iletişim Fakültesine Yönelik Bir Araştırma" Journal of Yasar University Vol: 20, Number: 5, Pg: 3348-3382. 